\title{
Symposium review: Building a better cow-The Australian experience and future perspectives ${ }^{1}$
}

\author{
J. E. Pryce, ${ }^{*} \dagger^{2}$ T. T. T. Nguyen, ${ }^{*}$ M. Axford, $\ddagger$ G. Nieuwhof, ${ }^{*} \ddagger$ and M. Shaffer $\ddagger$ \\ ${ }^{*}$ Agriculture Victoria, AgriBio, Centre for AgriBioscience, Bundoora, Victoria 3083, Australia \\ †School of Applied Systems Biology, La Trobe University, Bundoora, Victoria 3083, Australia \\ ‡DataGene Ltd., Bundoora, Victoria 3083, Australia
}

\section{ABSTRACT}

Genomic selection has led to opportunities for developing new breeding values that rely on phenotypes in dedicated reference populations of genotyped cows. In Australia, it has been applied to 2 novel traits: feed efficiency, which was released in 2015 as feed saved breeding values, and heat tolerance genomic breeding values, released for the first time in 2017. Feed saved is already included in the national breeding objective, which is focused on profitability and designed to be in line with farmer preferences. Our future focus is on traits associated with animal health, either directly or in combination with predictor traits, such as mid-infrared spectral data and, into the future, automated data capture. Although it is common for many evaluated traits to have genomic reliabilities ranging between 60 and $75 \%$, many new, genomic information-only traits are likely to have reliabilities of less than $50 \%$. Pooling of phenotype data internationally and investing in maintenance of reference populations is one option to increase the reliability of these traits; the other is to apply improved genomic prediction methods. For example, advances in the use of sequence data, in addition to gene expression studies, can lead to improved persistence of genomic breeding values across breeds and generations and potentially lead to greater reliabilities. Lower genomic reliabilities of novel traits could reduce the overall index reliability. However, provided these traits contribute to the overall breeding objective (e.g., profit), they are worth including. Bull selection tools and personalized genetic trends are already available, but increased access to economic and automatic capture farm data may see even better use of data to improve farm management and selection decisions.

Key words: breeding objective, novel trait, feed efficiency, heat tolerance

\footnotetext{
Received June 21, 2017.

Accepted December 14, 2017.

${ }^{1}$ Presented as part of the ADSA Multidisciplinary and International Leadership Keynote (MILK) Symposium at the ADSA Annual Meeting, Pittsburgh, Pennsylvania, June 2017.

${ }^{2}$ Corresponding author: jennie.pryce@ecodev.vic.gov.au
}

\section{INTRODUCTION}

Australia has more than 6,000 dairy farmers producing around 9.7 billion L of milk/yr (Dairy Australia, 2017). Around $34 \%$ of Australian milk production was exported in 2015-2016, with Asian countries being the largest market (e.g., China, Japan, Singapore, Malaysia, and Indonesia; Dairy Australia, 2017). The national herd size is 1.66 million cows, and around 0.7 million cows participate in milk recording (46\%). Around 30\% of the improvement in milk yield can be attributed to genetic improvement, with recent (2015-2016) estimates being an average of $6,983 \mathrm{~L} / \mathrm{cow}$ per lactation (Figure 1; DataGene, 2016).

Dairy farms are mainly located in temperate and subtropical areas of Australia. Around two-thirds of the dairy cow population is in Victoria (in the southeast part of the country), which is the most dominant dairy state. Although feeding with some supplementary grain is becoming more common, the Australian dairy industry remains predominantly pasture based. The diverse production environment coupled with reliance on pasture will continue to shape future selection objectives.

The aim of this article is to describe how genomic selection is changing current and future selection, especially with regard to new traits and the effect that this may have on selection indices. We also discuss opportunities to use mid-infrared (MIR) spectra and automated data capture to improve breeding value and phenotype prediction. In common with other countries, the traits that will be the main beneficiaries of these innovations are likely to be health traits that have become a major focus of our research. Finally, data capture, especially in an era of growth in farm automation, remains crucial in providing phenotypes for genomic prediction.

\section{GENOMIC REFERENCES POPULATIONS}

Until recently, genetic improvement in dairy cattle relied on using pedigree and phenotype data to estimate breeding values plus AI as a highly effective dissemination process. Genomic selection has replaced the 


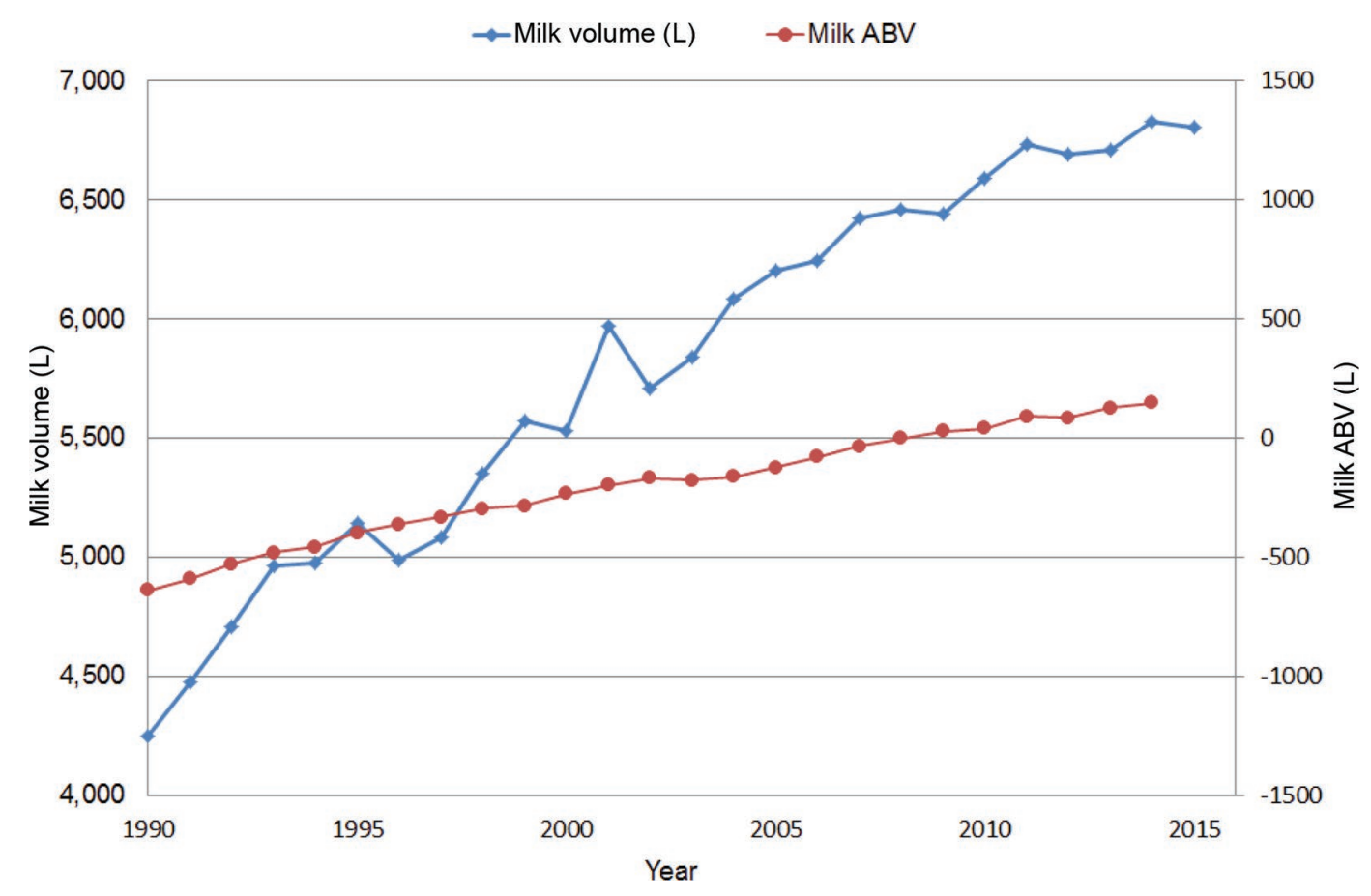

Figure 1. Average milk volume per cow (Holsteins) by year of production and milk Australian breeding value (ABV) by year of birth from 1990-1991 to 2015-2016 (DataGene, 2016). Color version available online.

requirement of waiting until a bull has progeny to make selection decisions because the breeding value can be estimated from marker effects derived from a reference population of animals with phenotypes and genotypes.

Most countries around the world rely on genomic reference populations that mainly comprise genotyped bulls with progeny groups. In the genomic era, a smaller number of young bulls are used heavily on the basis of their genomic proofs, so the progeny test paradigm of having a large cohort of bulls with progeny test groups is being replaced by a smaller number of bulls with larger progeny groups. Note that many genomically tested young bulls have small progeny groups due to limited production of semen. Some of them would have more daughters if they produced semen at the same rate as mature bulls. Through genomics we are already seeing generations turn over more rapidly so that by the time a bull's progeny are milking, he has been replaced by higher merit bulls. In the United States, the generation interval of sires to breed sires has decreased from $7 \mathrm{yr}$ to around $2.5 \mathrm{yr}$ as a result of genomic selection, with the generation interval of sires of cows decreasing from 7 to 5 yr (García-Ruiz et al., 2016). Consequently, the number of bulls with sufficient progeny to get a proof is declining and is likely to continue to do so as fewer bulls are used as sires of the next generation. There were 1,430 bulls born in 1990 and registered in
Australia that had sufficient daughters to get a milk production proof. For bulls born in 2001, the equivalent number was 402, which means that since 1990 the annual reduction in bulls getting production proofs by birth year has decreased by $60 / \mathrm{yr}$ on average (Figure 2). Similar patterns have been seen worldwide, with the number of bulls with daughter records decreasing dramatically (Hutchison et al., 2014; Weller et al., 2017). Furthermore, the incentive to collect information on a bull that may no longer be on the market is reduced.

Australia introduced genomic breeding values for Holsteins and Jerseys in 2010, initially through maleonly genomic reference populations. In response to a reduction in males contributing to the reference population in addition to opportunities to work with a small group of herds that are known to be good at recording phenotypes, a female reference population was initiated in Australia, known as the Genomic Information Nucleus (Ginfo) project. The Ginfo project is a largescale genotyping project of females from herds that were selected on the basis of the completeness of their phenotypic records.

Females were first added to the Australian reference population in April 2016. Currently, around 87\% of the Australian Holstein reference population is female. The addition of 17,108 and 3,347 Holstein and Jersey females, respectively, to the genomic reference popula- 
tions (in April 2016) has increased the reliability of genomic breeding values by 5.8 and $2.5 \%$ for young genotyped Holstein and Jersey bulls, respectively (Figure 3). These cows were from herds that had been specially selected based on the phenotypes that they contribute to breeding value estimation and represent around $3 \%$ of the milk-recorded population. The effect of the expanded reference population on genomic reliability varies by trait, with gains of between 5 and $7 \%$ for Holsteins and between 2 and 3\% for Jerseys. For example, in Holsteins, the reliability of daughter fertility increased from 41 to $46 \%$, whereas overall type increased from 42 to $49 \%$. Current reliabilities of genomic breeding values for bulls without daughters for balanced performance index (BPI) and protein yield are 61 and $74 \%$, respectively.

The Ginfo population is currently undergoing a period of expansion, taking the number of herds from 100 ( $\sim 30,000$ cows $)$ to $200(\sim 60,000$ cows $)$. The industry benefit of increasing the size of the reference population has been determined using a cost-benefit analysis that considered the magnitude of predicted increases in reliability for 3 trait groups (the overall breeding objective, health, and conformation). A method to calculate the theoretical economic contribution of adding more phenotypes to a genomic reference population was applied (Gonzalez-Recio et al., 2014). Briefly, the change in overall profitability was assessed using the breeder's equation (Lush, 1945) applied to each of the trait areas. The response to selection calculated from the breeder's equation is the selection intensity multiplied by the square root of the reliability and additive genetic standard deviation divided by the generation interval. Only the reliability was altered according to the size of the reference population using the equation of Daetwyler et al. (2008). As the reference population size gets larger, the increase in reliability (and subsequent benefit) per phenotype added to the reference population diminishes, whereas the cost of genotyping and phenotyping remain constant per additional animal. Beyond 200 herds, the incremental gains in reliability from having a larger reference population were not sufficient to justify the extra cost (Pryce and Shaffer, 2018).

In addition to adding a large number of females to the genomic reference population, single-step methodologies incorporating very large populations of cows with genotypes and phenotypes are changing the way breeding values are estimated (Weller et al., 2017). The most common single-step approaches replace part of the pedigree relationship matrix with genomic relationships. To date, in many studies of single-step methods, the genotyped proportion of the reference population is low, which Weller et al. (2017) argued may lead to convergence issues. However, the proportion of genotyped females is rapidly increasing, which may facilitate single-step approaches. We estimate that around 9\%

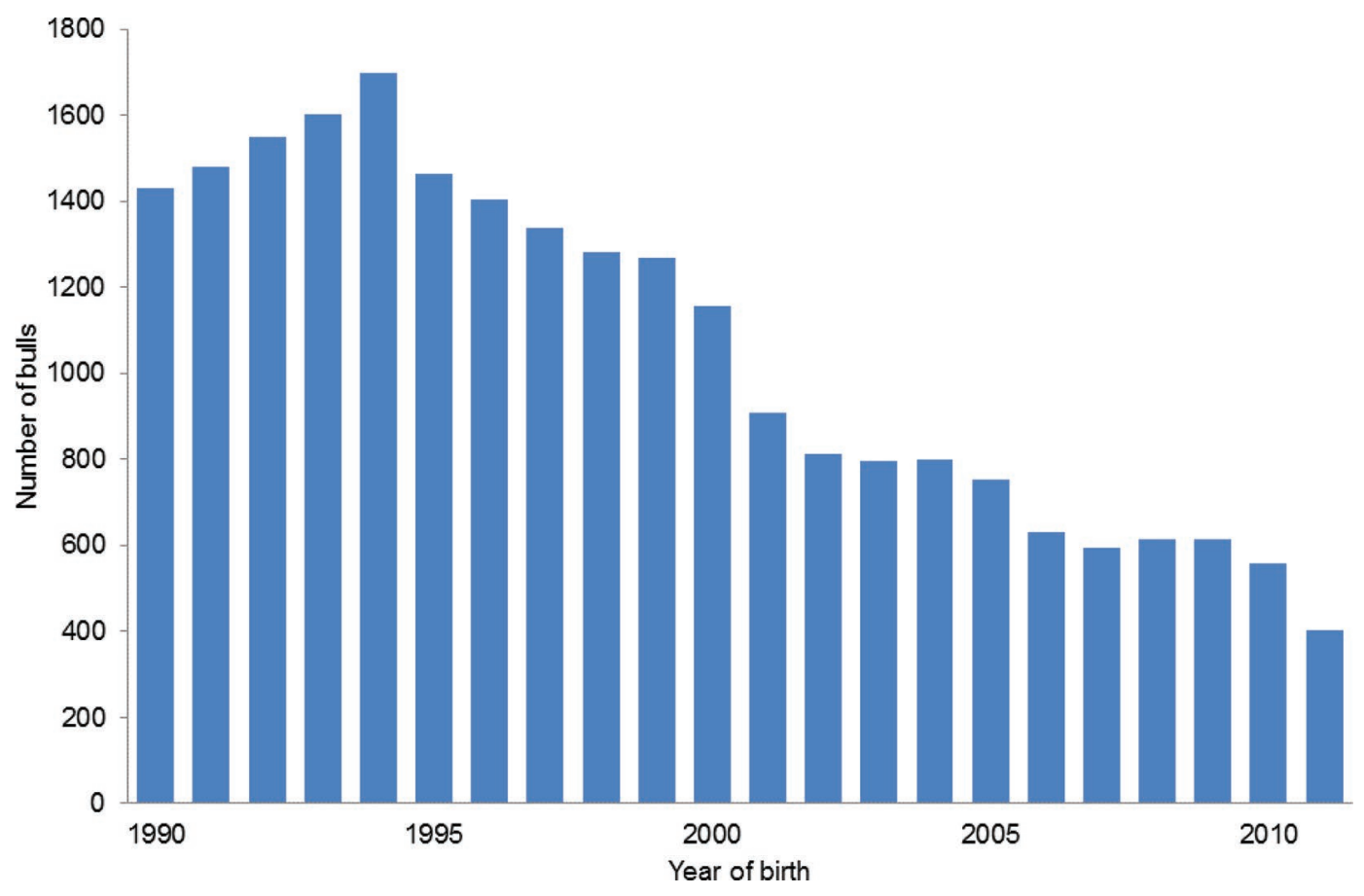

Figure 2. Number of bulls by year of birth with publishable proofs for milk production traits. Color version available online. 


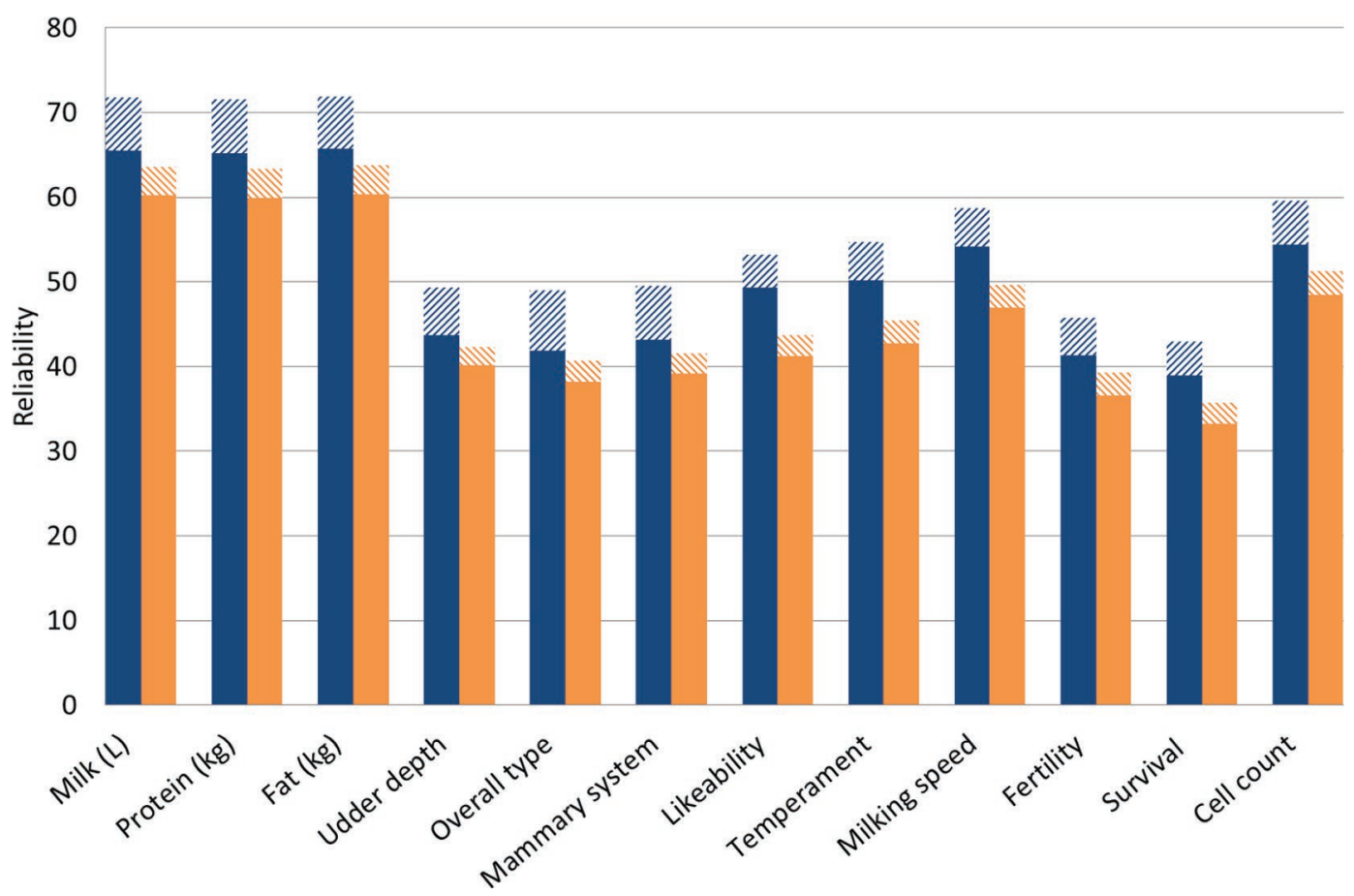

Figure 3. Reliabilities of evaluated traits using genomic information only for Holsteins (black bars) and Jerseys (gray bars) with (solid and hatched lines) and without (solid only) the addition of the Genomic Information Nucleus (Ginfo) project. Color version available online.

of the Australian population that participates in milk recording is genotyped, as Ginfo herds were selected for contribution of phenotype data to genetic evaluations. It is likely that the proportion of genotyped cows with fertility or health records will be much higher. In the United States, the number of genotyped Holstein females has exceeded 1.5 million (https://queries.uscdcb .com/Genotype/cur_freq.html; Council on Dairy Cattle Breeding, 2017a), with very large female populations also being genotyped in France and Ireland, among others.

Single-step genomic best linear unbiased prediction is already officially available in several countries, including Belgium and the Czech Republic. A limitation is integrating breeding values from other countries when the raw data are not available. Generally, information from foreign data is tackled using multiple acrosscountry evaluation of sires, where breeding values are deregressed and used as phenotypes for genomic prediction. Vandenplas et al. (2017) developed a national single-step method that used multinational genomic information and applied this to Brown Swiss national evaluation in Slovenia.

Information from gene expression, or genome-wide association analyses, can be used to further improve the accuracy of selection. Genome-wide association studies are often used to identify regions of the genome that have a specific effect on a trait of economic importance. Sometimes these can be linked to candidate genes, which help our understanding of the genetic control of complex traits and, if large enough, can be selected on directly. Whole-genome sequencing has been shown to improve the resolution and detection of causative mutations of these candidate SNP in addition to increasing the accuracy of genomic prediction (MacLeod et al., 2016). More variants of importance are likely to be identified, and the challenge will be to apply this knowledge, especially as including all sequence variants is unattractive because of the computational time required. One option is to use this as prior information in new genomic selection methods that allow SNP to be categorized according to their effect (MacLeod et al., 2016). An alternative is to augment genomic relationship matrices to include a subset of SNP (Khansefid et al., 2014; Tiezzi and Maltecca, 2015). By including SNP that explained variation in fertility traits, Ortega et al. (2016) were able to increase the reliability of the USA PTA for daughter pregnancy rate by $0.20 \%$. VanRaden et al. (2017) were able to increase the average reliability of genomic selection by $2.7 \%$ (from 64.7 to $67.4 \%$ ) by using selection of variants from genome sequence data. The increase in reliability is estimated to be worth around $\$ 3$ million/yr to the US dairy population. The Australian feed saved breeding value (described in de- 
tail in the next section) includes a genomic prediction equation for residual feed intake (RFI; Pryce et al., 2015). The highest accuracy was achieved when extra weight in the genomic relationship matrix was placed on SNP from beef cattle populations identified using genome-wide association studies for RFI (Khansefid et al., 2014).

As SNP density increases, so does the probability of a QTL and SNP being in perfect linkage disequilibrium. Therefore, the responsible mutations are expected to already be in whole-genome sequence data, although they are among many SNP with no effect (Meuwissen et al., 2016). If the SNP are the causative mutation, then in theory at least the ability to do genomic predictions across breed is improved, as the linkage disequilibrium should persist across breeds. One of the current challenges is that whole-genome sequence data are hampered by genotype errors at low coverage (Meuwissen et al., 2016). If this can be overcome, then ultimately sequencing may become the preferred method of genotyping, especially if the cost continues to decrease.

An alternative is to use genotyping by sequencing, in which just a fraction of the genome is sequenced. One of the drawbacks with genotyping by sequencing is that the quality of genotypes is generally lower than SNP array data, as it depends on the genome-wide depth of sequencing. However, the cost of genotyping using genotyping by sequencing is a lot lower than SNP arrays, and some of the drawbacks can be overcome by imputation and error correction methods. Gorjanc et al. (2015) found that the accuracy of genomic prediction can be maximized by genotyping large numbers of individuals at low coverage for a large number of markers.

\section{BREEDING VALUES FOR NOVEL TRAITS}

Genomic selection can lead to opportunities in developing genomic breeding values for other traits of economic importance. Recently, Egger-Danner et al. (2015) reviewed candidate traits for new breeding values. In this article, we focus on the Australian dairy industry, which is developing health breeding values, in addition to 2 breeding values that have recently been developed in Australia. The first is a breeding value for feed efficiency, known as feed saved, and the second is heat tolerance.

\section{Health}

Through progeny testing, breeding values typically were estimated using daughter groups that had mea- surements on either the breeding objective itself or traits correlated with it. For example, SCC is measured through commercial milk recording and is usually available on many daughters of a given bull and can be used to calculate breeding values for that bull.

Somatic cell count has a correlation of around 0.6 with clinical mastitis (Mrode and Swanson, 1996), so selection for SCC can be used to manipulate the incidence of clinical mastitis. This approach works reasonably well, as can be seen in Figure 4. However, a superior approach may be to select for mastitis directly. The challenge in many countries (including Australia) is to gather a data set of sufficient size for estimation of breeding values. Genomic selection may facilitate this, especially if some of the phenotypes are measurable only in dedicated female reference populations.

We are currently developing health breeding values with a special focus on the phenotypic clinical observations of disease collected in the Ginfo herds (including mastitis, lameness, and reproductive disorders). Our experience to date is that using a reference population of around 10,000 genotyped cows for genomic prediction of low-heritability traits (e.g., health disorders such as mastitis) results in a low reliability of genomic prediction (<40\%; Abdelsayed et al., 2017). For many traits, including mastitis, a multitrait index that includes several predictors such as SCC, clinical cases, and udder conformation may increase the accuracy of genomic prediction. Other predictors, perhaps automated sensor data, could improve the accuracy of prediction further still. For other health traits, predictors may come from advances in automated data capture and innovative use of predictors (discussed later).

\section{Feed Saved}

Feed efficiency is an important breeding goal because feed is a major cost variable in livestock production systems. Over the last $60 \mathrm{yr}$, milk production per unit of BW has doubled, so efficiency has improved because of dilution of maintenance requirements. However, there is also variation in the way that animals convert feed into product, which can be evaluated using RFI. Residual feed intake is the difference between actual and predicted feed intake and is thought to capture variation in activity, protein turnover, heat increment, and digestibility (Berry and Crowley, 2013). Residual feed intake requires measurements of feed intake, which is expensive and time consuming to collect and usually available only in research herds. Genomics with multicountry collaboration has revolutionized the way we select for feed efficiency in cattle (de Haas et al., 2015) by using data collected on a small scale to generate 
genomic breeding values that enable genomic selection in an entire population.

From April 2015, feed saved ABV have been available in Australia, and feed saved is included as a trait in the national selection indices of Australia. Feed saved is defined as the amount of feed that is saved through improved metabolic efficiency and reduced maintenance requirements. The breeding value includes a genomic component for RFI combined with an EBV for BW predicted from type traits. Animals that have EBV that are $1 \mathrm{SD}$ above the mean are predicted to eat $65 \mathrm{~kg}$ of DM less per year at the same level of milk production. The mean reliability of the feed saved EBV was $37 \%$ in 4,416 genotyped Holstein sires without phenotypes.

Maintenance of a genomic reference population with measured phenotypes is an ongoing challenge. A network of research herds is a cost-effective way to achieve this, although internationally genotype $\times$ environment interactions come into play. For some phenotypes of interest there are additional challenges, such as consistent ways of measuring the phenotype. For example, there are several ways to measure methane emissions. One way to analyze this type of data is to treat each reference population (i.e., herd's data) as a different trait in a multitrait model. This approach has already been applied to analyze feed intake data from multiple research farms from several different countries and deals with genotype $\times$ environment interactions and differences in phenotype recording simultaneously (de Haas et al., 2015). Environmental drivers around the role of ruminants in global warming and climate change are likely to see selection for both feed efficiency and methane emissions remain high on the list of selection objectives worldwide.

\section{Heat Tolerance}

The other aspect to global warming is the effect of increasing temperatures on the cow itself. In Australia, it is projected that major dairying regions will experience an increase in daily average temperatures in addition to more frequent heat waves of longer duration. Therefore, mitigating the effects of the warming climate on animal performance is of great importance.

Several efforts have been made to reduce the effects of heat stress in Australian dairy cattle, such as the Cool Cows initiative of Dairy Australia (http://www .coolcows.com.au/). There are also promising opportunities to use genetics to alleviate heat stress. For example, breed differences have already been identified, as New Zealand Holsteins appear to exhibit greater reductions in milk yield in hotter climates than Jerseys or crossbreds (Bryant et al., 2007a). In fact, in New Zealand, reductions in yield start when temperatures

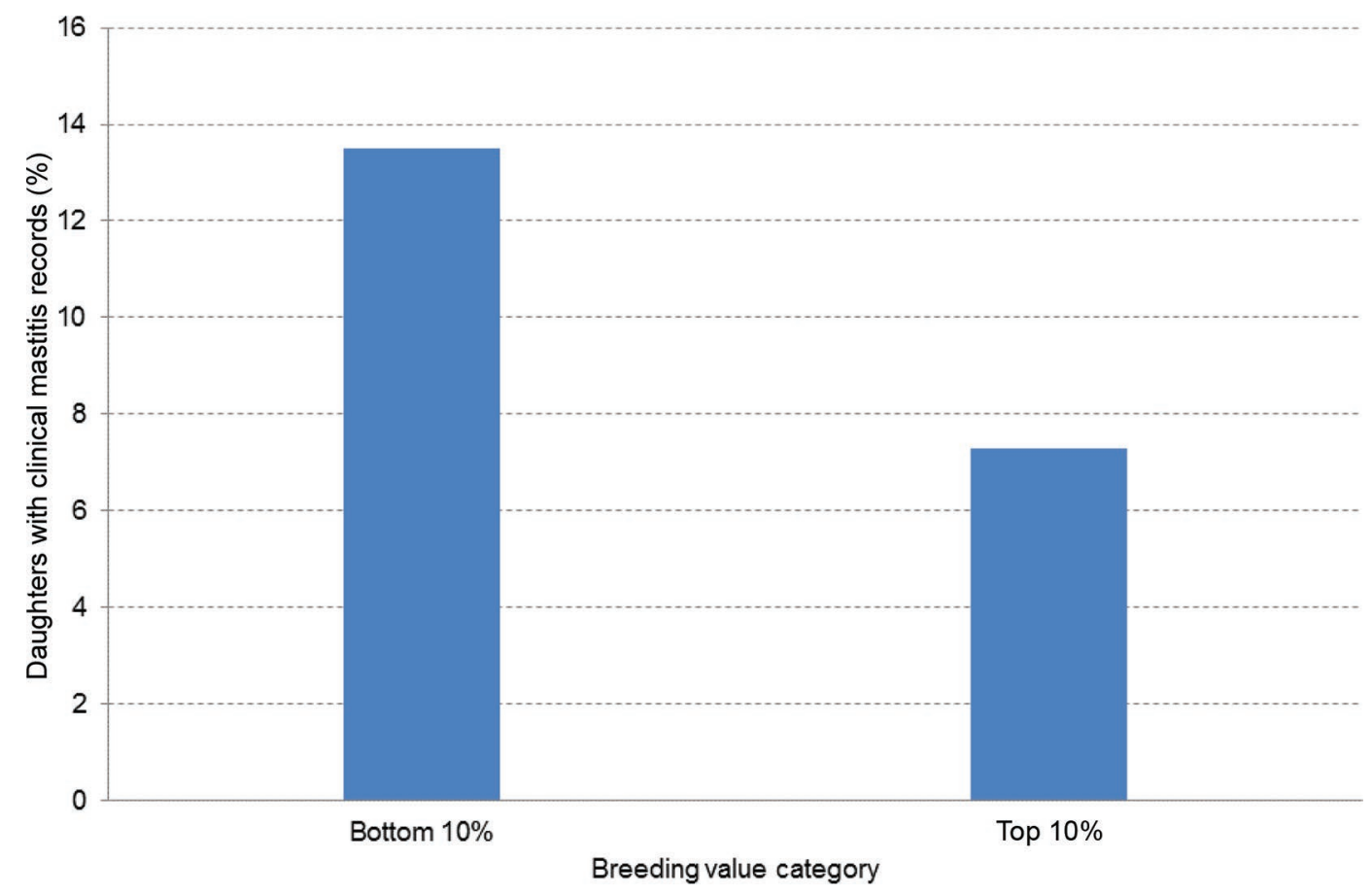

Figure 4. Percentage of recorded cases of clinical mastitis in 1,934 Holstein sires that are divergent (top and bottom 10\%) for Australian national genetic evaluations of SCC breeding values. Color version available online. 
exceed 21 and $25^{\circ} \mathrm{C}$ at $75 \%$ humidity for Holsteins and Jerseys, respectively (Bryant et al., 2007b).

Declining milk, fat, and protein yields as temperature and humidity increase (defined using a temperature-humidity index) are often used as indicators of exposure to heat stress events (Ravagnolo and Misztal, 2000; Hayes et al., 2003; Nguyen et al., 2016). Nguyen et al. (2016) found that heat tolerance genomic breeding values can be predicted with an accuracy of 0.42 to 0.61 using high-density SNP genotypes. Heat tolerance genomic breeding values are unfavorably correlated with production traits but have favorable correlations with fertility (Nguyen et al., 2016), confirming the relationship found by Ravagnolo and Misztal (2002). Furthermore, genomically predicted heat-susceptible and predicted heat-tolerant animals show significant difference in milk yield losses and rectal and intravaginal temperatures when experiencing a mild simulated heat wave (Garner et al., 2017). Since these studies, additional animals have been added to the reference population (mainly genotyped females), and reliabilities (i.e., the square of the accuracy) are now typically around $40 \%$ for bulls with no progeny (Nguyen et al, 2017a). Breeding values for heat tolerance were released for the first time in Australia in 2017.

Regional differences may have an effect on the economic value of selecting for heat tolerance. For instance, in warmer climates, where the environmental heat load is higher, there may be greater justification in selecting sires that are predicted to have daughters that are more heat tolerant than regions with lower heat load. Nguyen et al. (2017b) used projected climate data from Commonwealth Scientific and Industrial Research Organisation (Canberra, Australia) and the Bureau of Meteorology to determine levels of heat load for most dairying regions in Australia, which also serves as a weight for heat tolerance in an augmented BPI index. The Pearson product-moment correlation between BPI and the BPI that includes heat tolerance (with weights appropriate for a high-temperature-humidity index environment) is around 0.95, which implies that there is currently no justification to have regionally specific indices

\section{SELECTION INDICES}

As breeding objectives become more complicated, it is important to ensure that all (measured) traits contributing to profit are included in selection decisions. Parents of the next generation should be selected using the local national selection index, as these are generally based on economics and genetic parameters relevant to the country.
Over time, national dairy selection indices have evolved to have more traits and now include not only returns from dairying (typical of selection indices up until the late 1990s and early 2000s) but also costs of production, including feed, health, reproduction, and longevity (Miglior et al., 2017). In fact, many countries now have more than 6 trait categories (milk production, type, longevity, udder health, fertility, other) in their national selection objectives (Egger-Danner et al., 2015).

New traits will inevitably be added in the future to meet the concerns set by consumers and the broader society (Boichard and Brochard, 2012; Martin-Collado et al., 2015). In cases where there is rationale to deviate from the economically derived index weight, there are approaches to calculate nonmarket values (Nielsen et al., 2005), the idea being that this can be used to capture either consumer or farmer perceptions on the value of traits that are not quantifiable using a standard economic framework.

Another challenge is encouraging farmer use of domestic selection indices. Even though multitrait selection indices were available, many Australian farmers did not prioritize them in their own breeding objective. This led to a new approach and the development of 3 national selection indices for Australia, giving farmers a choice of index that aligned to their own breeding philosophy (Byrne et al., 2016).

A method to derive nonmarket values, known as "1,000 minds," has been used (Martin-Collado et al., 2015) as the foundation for the new national selection indices. The 1,000 minds approach works through a questionnaire type of approach, where the respondent is asked to compare a series of items in which each contrast is of similar value. Provided a large enough survey is undertaken, these contrasts can be used to determine nonmarket values.

\section{Selection Indices for Australian Dairy Cattle}

Through the 1,000 minds approach, Martin-Collado et al. (2015) found that (1) there is a continuum of breeding preferences rather than defined groups of farmers; (2) differences in preferences were linked to drivers of production systems, such as calving pattern and feeding system; and (3) improved udders and type were important to many dairy farmers and were not linked to the proportion of the herd registered with a breed society. The traits for which the surveyed farmers had the strongest preference (i.e., the largest deviation from the economic value) were (1) mastitis, (2) longevity, (3) fertility, (4) mammary system, (5) lameness, (6) protein yield, (7) type, (8) feed efficiency, (9) calving 
ease, (10) temperament, (11) lactation persistence, and (12) live weight.

In April 2015, the Australian Dairy Herd Improvement Scheme (the predecessor to DataGene) released 3 selection indices: (1) the BPI, which is focused on profitability and designed to be in line with farmer preferences defined in the 1,000 minds study of MartinCollado et al. (2015); (2) the health weighted index, which is predicted to result in greater selection responses for health, fertility, and survival traits; and (3) the type weighted index, which places additional selection pressure on conformation traits, particularly those associated with longevity and udder conformation. The correlations between BPI and the type weighted index and health weighted index were 0.94 and 0.98 , respectively, when reported on a list of published Holstein bulls born between 1990 and 2009 ( $\mathrm{n}=5,213$; Byrne et al., 2016). Although these correlations show that the indices are very similar, the aim is to appeal to as many farmers as possible.

\section{Monitoring Rates of Genetic Gain}

Individual rates of genetic gain at a national and even at a farm level are objective ways to determine the historical success of national and herd-level breeding objectives. Since 2013, Australian herd recording dairy farmers have had access to genetic progress reports that monitor within-herd genetic trends for BPI and 6 economically important traits. This decision-making tool has been successful in helping farmers visualize genetic change within their herd and prompt change in genetic selection practices.

In theory, provided the total merit index values capture many of the factors affecting profitability, they should align reasonably well with per-cow net profit (within herd). Using data from 3 Australian herds, high genetic merit cows (i.e., the top $50 \%$ of cows within a herd ranked on BPI) contributed between $\$ 150$ and $\$ 235 /$ cow more to net farm profit per year without compromising longevity or incurring higher breeding or mastitis treatment costs (Newton et al., 2018). Surprisingly, this type of validation exercise has not been widely applied, yet it is important in convincing farmers to use economic selection indices. There are a few exceptions. For example, Ramsbottom et al. (2012) found that the correlation between the Irish breeding index and the net margin per cow was 0.22 and that the regression coefficient was about $€ 2$ per unit increase in Irish breeding index, which aligns with expectations, as the Irish breeding index is evaluated in predicted transmitting abilities. The results from these studies are valuable in demonstrating that se- lecting on selection indices will lead to improved farm profitability.

\section{Effect on Reliability of Adding Genomic-Only Breeding Values to Selection Indices}

Many of the new traits that we have described have much lower genomic reliabilities than traditional traits. This is mainly because the reference populations comprise comparatively few individuals that have measurements on the phenotype of interest. Therefore, although traditional traits now have reliabilities ranging between 61 and $75 \%$ for young genomic bulls (e.g., Council on Dairy Cattle Breeding, 2017b), many new, genomic-only traits will have reliabilities of less than $50 \%$. For example, feed saved has a mean reliability of 37\% (Pryce et al., 2015). Increasing the reliability of new genomic-only breeding values, such as advancing genomic prediction methodologies or extending reference populations to include more genotyped animals with phenotypes of interest (Gonzalez-Recio et al., 2014; Chesnais et al., 2016), is important.

Provided that each trait added to a selection index explains some of the variation in net profit, then adding more traits to the breeding objective will result in incremental gains in overall profit. As lower reliability traits are included in a selection index, the overall reliability of the index reduces, which may affect breeder confidence in selecting on the index, as reranking and individual bull movement will be greater.

The counterargument to this is that farmers should always be encouraged to invest in a team of bulls instead of a single bull (a team of 10 bulls with individual reliability of $58 \%$ is $96 \%$ ). However, in most countries in the world, bulls are assessed individually and breeding value movements are closely scrutinized.

\section{PHENOTYPING OPPORTUNITIES}

\section{Mid-Infrared Spectral Data}

A way of scaling up the number of phenotypes available for genomic prediction is to use MIR spectral data analysis to predict complex phenotypes that are measurable only in small (research) populations (Gengler et al., 2016). In addition to traditional traits (e.g., fat, protein, casein), MIR analysis of milk has been used to predict other milk characteristics such as fatty acid composition, milk protein composition, milk coagulation properties, milk acidity, mineral composition, and ketone bodies (De Marchi et al., 2014; Gengler et al., 2016). Here we use ketosis as an example of how MIR spectral data could be used for genomic prediction. 


\section{Predicting Ketosis}

There is evidence that MIR can be used to predict metabolic disease biomarkers and many other phenotypes of value to the dairy industry (De Marchi et al., 2014). Approximately $75 \%$ of dairy cow disease occurs in the first month after calving (LeBlanc et al., 2006). Hence, there is good justification to focus on traits and diseases arising in the transition period and early lactation. For Australia, in common with many other countries, reducing early-lactation disease would have economic and welfare benefits. Consequently, ketosis is a trait that is in the research phase of development.

Ketosis is an example of a disease that could be managed using evaluations based on MIR phenotypes. The hypothesis is that MIR spectral data analysis can be used to detect the ketone bodies present in milk. Ketone bodies are synthesized in the liver from acetyl-coA and are important for energy production (Jorritsma et al., 1998). The major ketone bodies are BHB, acetoacetate, and acetone.

The gold standard method of diagnosing ketosis is using BHB in blood. The potential to predict acetone and BHB contents using MIR has been tested by several authors (van Knegsel et al., 2010; Grelet et al., 2016; Belay et al., 2017), who all concluded that MIR predicted ketone bodies adequately and that MIR might be useful for screening purposes (healthy cows vs. cows at risk of ketosis). In fact, Grelet et al. (2016) found that the accuracy of predicting the risk of ketosis using MIR was $85 \%$ when assessed using circulating levels of BHB and nonesterified fatty acids.

How to use phenotypes predicted from MIR is a growing area of research. For example, predictions of BHB from MIR could be used as one trait and clinical cases of ketosis used as another trait in a genetic multitrait prediction model of ketosis. There are also considerations in terms of the longitudinal nature of the data. Additionally, fat:protein ratio and other energy balance traits could be included as predictors. It is also possible that by making genetic improvement in one trait, correlated responses (improvements) in other metabolic diseases could be achieved, although this is yet to be tested. The heritability of BHB, estimated using genomic relationship matrices, has been estimated to be between 0.05 and 0.09 in US Holsteins (Weigel et al., 2017). Using an $\mathrm{H}$ matrix (i.e., pedigree and genomic relationships), the heritability of recorded cases of clinical ketosis data was found to be very similar (0.09; Parker Gaddis et al., 2014).

Another prospect is using information from MIR and genomic data together to improve the accuracy of phenotypic performance. This area is very much in its infancy but could be a good way of using multiple predictors of current and future performance.

\section{Farm Automation and Sensors}

Increasing herd size, a drive for improved farm efficiency, and availability of sensors and automated image capture are reasons why there is a move toward precision farm management (Eastwood et al., 2016). Although providing data for genetic evaluations is by no means the primary use of automated data capture technologies, it is possible to use the data for this purpose provided that the information captured is accurate. One of the biggest opportunities is to use these technologies to provide more objective phenotypes. For example, body condition scoring and locomotion scoring currently are largely subjective. However, by using image analysis, objective ways of accessing phenotypes for these traits are possible. Validation of some of these technologies looks promising. For example, the correlation between automatically sensed BCS and conventional scoring was 0.94 (Halachmi et al., 2013).

The growth in data from sensors and other precision dairy technologies has dramatically increased the amount of data available on a wider pool of cows than has historically been the case in Australia. However, these data exist in islands and do not flow into industry databases where they can be matched with existing data. The Australian dairy industry has recognized this as an issue and is constructing a central data repository to allow data from multiple systems, from inline milk sensors to pedometers, from breed society pedigree data to milking equipment software, to move easily from system to system. The central data repository should both increase the ease of farmer data recording and increase the amount of phenotypic information available for genetic evaluation. Another consideration is having recording procedures in place. The International Committee on Animal Recording (Rome, Italy) has established a task force to develop protocols and standards for new sensors and automated recording devices. Developing calibration and quality certification of new sensor data to show that machines produce repeatable and comparable results is an important area that requires further work.

To enable farmers to have access to single-entry, multiuse data, commercial reality dictates that service providers and the industry, including research institutions, must find a win-win outcome that allows service providers to deliver new or improved services to their clients and allows industry to access the data. In the Australian context, this requires that commercial interests be balanced with industry good interests and a 
common access framework to unleash the innovation, which should come from newly integrated data sources. For instance, for the first time in Australia, detailed farm financial information is being matched to detailed genetic information to show the effect of genetics on profit (Newton et al., 2018). This sort of cooperation is made somewhat easier in Australia by the comparatively limited number of commercial players in the herd improvement industry and the articulation of a common industry vision.

\section{DELIVERY MECHANISMS}

There are 2 main angles that the Australian herd improvement industry is taking to deliver better profitability into the future: data integration and genetic evaluation service changes. With data, the industry is looking to create a system of near-time exchange between all major on-farm systems and industry databases. This will require an updated data grading system to ensure that data in the central data repository are fit for purpose. Not all data will be suitable for genetic evaluation, but they might be suitable for management decisions. Service providers will have the opportunity to provide new services driven by integrated data, such as the ability to model the future profitability effects of mating, treating, and feeding decisions. This change from reactive, backward-facing analysis to proactive, predictive analytics is significant. It will help meet the industry vision of turning data into information - not just reporting to a farmer what has happened on their farm via a static dashboard, but suggesting interventions to improve farm business performance. Both the dashboard analysis and the more detailed predictive analytics should be available to farmers and industry wherever they are and whenever they need them.

On the genetic evaluation front, this means a desire to empower farmers to make their breeding and management decisions in a time frame that meets their needs. This could mean, for instance, that genetic evaluation becomes an on-demand system that runs in the cloud continually, giving farmers and industry effectively a live breeding value. If this could be coupled with a cowside genotyping test, the effect of such a system would be profound. In addition, combining the genomic information of the evaluation system with the management information of the data system should allow farmers to make more informed decisions. Do you put another straw of semen into a heifer with low genetic merit for fertility? Do you treat that second case of mastitis in a cow with low genetic merit for mastitis resistance?

While focusing phenotype collection on new traits that are economically important to farmers, such as health resistance, traditional breeding values will need continual maintenance to maintain accuracies. In Australia, this is particularly true for traits such as fertility and type, where phenotype collection and data integration will become more important in a post-progeny test world. The design of this new progeny verification framework has not yet been fully specified, but it must include interactions with new data providers and scientists.

\section{CONCLUSIONS}

Genomic selection is ideally suited to difficult-tomeasure traits that can be used to build a better cow. Already it has revolutionized the choice of traits and consequent composition national selection indices used in Australia. Feed saved and heat tolerance Australian breeding values are available only because of genomic selection. The establishment of a female genomic reference population and the use of new technologies and advancement in automated phenotyping will see a new wave of genomic breeding values. One challenge is that, currently, breeding values of new traits that rely on a dedicated reference population have lower reliabilities, which, when added to the national selection index, will erode the overall reliability and could lead to more reranking of sires than seen in the past. Advances in genomic prediction methodology and regular refreshment of the reference population should alleviate some of these issues by being instrumental in increasing reliabilities.

\section{ACKNOWLEDGMENTS}

Jennie Pryce and Thuy Nguyen gratefully acknowledge funding from DairyBio, which is a joint venture from Dairy Australia (Melbourne, Australia) and Agriculture Victoria (Melbourne, Australia). Iona MacLeod and Mary Abdelsayed (Agriculture Victoria) and Tim Hancock (DataGene Ltd., Melbourne, Australia) are thanked for their contribution to the article.

\section{REFERENCES}

Abdelsayed, M., M. Haile-Mariam, and J. E. Pryce. 2017. Genetic parameters for health traits using data collected from genomic information nucleus herds. J. Dairy Sci. 100:9643-9655.

Belay, T. K., B. Dagnachew, Z. Kowalski, and T. Ådnøy. 2017. An attempt at predicting blood $\beta$-hydroxybutyrate from Fourier-transform mid-infrared spectra of milk using multivariate mixed models in Polish dairy cattle. J. Dairy Sci. 100:6312-6326.

Berry, D. P., and J. Crowley. 2013. Cell Biology Symposium: Genetics of feed efficiency in dairy and beef cattle. J. Anim. Sci. 91:15941613.

Boichard, D., and M. Brochard. 2012. New phenotypes for new breeding goals in dairy cattle. Animal 6:544-550. 
Bryant, J. R., N. Lopez-Villalobos, C. Holmes, J. Pryce, G. Pitman, and S. Davis. 2007a. The effect of level of feeding, genetic merit, body condition score and age on biological parameters of a mammary gland model. Animal 1:175-183.

Bryant, J. R., N. López-Villalobos, J. E. Pryce, C. W. Holmes, and D. L. Johnson. 2007b. Quantifying the effect of thermal environment on production traits in three breeds of dairy cattle in New Zealand. N. Z. J. Agric. Res. 50:327-338.

Byrne, T. J., B. Santos, P. Amer, D. Martin-Collado, J. Pryce, and M. Axford. 2016. New breeding objectives and selection indices for the Australian dairy industry. J. Dairy Sci. 99:8146-8167.

Chesnais, J. P., T. Cooper, G. Wiggans, M. Sargolzaei, J. Pryce, and F. Miglior. 2016. Using genomics to enhance selection of novel traits in North American dairy cattle. J. Dairy Sci. 99:2413-2427.

Council on Dairy Cattle Breeding. 2017a. Genotype counts by chip type, breed code, and sex code. Accessed Dec. 24, 2017. https:// queries.uscdcb.com/Genotype/cur_freq.html.

Council on Dairy Cattle Breeding. 2017b. Comparison of December with August evaluations for genomic young bulls. https://queries .uscdcb.com/eval/summary/chgaiG.cfm.

Daetwyler, H. D., B. Villanueva, and J. A. Woolliams. 2008. Accuracy of predicting the genetic risk of disease using a genome-wide approach. PLoS One 3:e3395.

Dairy Australia. 2017. Dairy at a glance. https://www.dairyaustralia .com.au/industry/farm-facts/dairy-at-a-glance.

DataGene. 2016. Australian dairy herd improvement report 2016. https://datagene.com.au/sites/default/files/DirectoryPage/Herd \%20Improvement\%20Report/2016\%20Australian\%20Dairy\%20 Herd\%20Improvement\%20Report.pdf.

de Haas, Y., J. Pryce, M. Calus, E. Wall, D. Berry, P. Løvendahl, N. Krattenmacher, F. Miglior, K. Weigel, and D. Spurlock. 2015. Genomic prediction of dry matter intake in dairy cattle from an international data set consisting of research herds in Europe, North America, and Australasia. J. Dairy Sci. 98:6522-6534.

De Marchi, M., V. Toffanin, M. Cassandro, and M. Penasa. 2014. Invited review: Mid-infrared spectroscopy as phenotyping tool for milk traits. J. Dairy Sci. 97:1171-1186.

Eastwood, C., J. Jago, J. Edwards, and J. Burke. 2016. Getting the most out of advanced farm management technologies: Roles of technology suppliers and dairy industry organisations in supporting precision dairy farmers. Anim. Prod. Sci. 56:1752-1760.

Egger-Danner, C., J. Cole, J. Pryce, N. Gengler, B. Heringstad, A Bradley, and K. Stock. 2015. Invited review: Overview of new traits and phenotyping strategies in dairy cattle with a focus on functional traits. Animal 9:191-207.

García-Ruiz, A., J. B. Cole, P. M. VanRaden, G. R. Wiggans, F. J. Ruiz-López, and C. P. Van Tassell. 2016. Changes in genetic selection differentials and generation intervals in US Holstein dairy cattle as a result of genomic selection. Proc. Natl. Acad. Sci. USA 113:E3995-E4004

Garner, J. B., M. Douglas, S. O. Williams, W. Wales, L. Marett, T. Nguyen, C. Reich, and B. Hayes. 2017. Corrigendum: Genomic selection improves heat tolerance in dairy cattle. Sci. Rep. 7:39896.

Gengler, N., H. Soyeurt, F. Dehareng, C. Bastin, F. Colinet, H. Hammami, M.-L. Vanrobays, A. Lainé, S. Vanderick, and C. Grelet. 2016. Capitalizing on fine milk composition for breeding and management of dairy cows. J. Dairy Sci. 99:4071-4079.

Gonzalez-Recio, O., M. Coffey, and J. Pryce. 2014. On the value of the phenotypes in the genomic era. J. Dairy Sci. 97:7905-7915.

Gorjanc, G., P. Bijma, and J. M. Hickey. 2015. Reliability of pedigreebased and genomic evaluations in selected populations. Genet. Sel. Evol. 47:65.

Grelet, C.. C. Bastin, M. Gelé, J.-B. Davière, M. Johan, A. Werner, R. Reding, J. F. Pierna, F. Colinet, and P. Dardenne. 2016. Development of Fourier transform mid-infrared calibrations to predict acetone, $\beta$-hydroxybutyrate, and citrate contents in bovine milk through a European dairy network. J. Dairy Sci. 99:4816-4825.

Halachmi, I., M. Klopčič, P. Polak, D. Roberts, and J. Bewley. 2013. Automatic assessment of dairy cattle body condition score using thermal imaging. Comput. Electron. Agric. 99:35-40.
Hayes, B. J., M. Carrick, P. Bowman, and M. E. Goddard. 2003. Genotype $\times$ environment interaction for milk production of daughters of Australian dairy sires from test-day records. J. Dairy Sci. $86: 3736-3744$.

Hutchison, J. L., J. B. Cole, and D. M. Bickhart. 2014. Short communication: Use of young bulls in the United States. J. Dairy Sci. 97:3213-3220.

Jorritsma, R., S. Baldee, Y. Schukken, T. Wensing, and G. Wentink. 1998. Evaluation of a milk test for detection of subclinical ketosis. Vet. Q. 20:108-110.

Khansefid, M., J. Pryce, S. Bolormaa, S. Miller, Z. Wang, C. Li, and M. Goddard. 2014. Estimation of genomic breeding values for residual feed intake in a multibreed cattle population. J. Anim. Sci. 92:3270-3283

LeBlanc, S. J., K. Lissemore, D. Kelton, T. Duffield, and K. Leslie. 2006. Major advances in disease prevention in dairy cattle. J. Dairy Sci. 89:1267-1279.

Lush, J. L. 1945. Animal Breeding Plans. 3rd ed. Iowa State University Press, Ames.

MacLeod, I. M., P. Bowman, C. Vander Jagt, M. Haile-Mariam, K. Kemper, A. Chamberlain, C. Schrooten, B. Hayes, and M. Goddard. 2016. Exploiting biological priors and sequence variants enhances QTL discovery and genomic prediction of complex traits. BMC Genomics 17:144.

Martin-Collado, D., T. Byrne, P. Amer, B. Santos, M. Axford, and J. Pryce. 2015. Analyzing the heterogeneity of farmers' preferences for improvements in dairy cow traits using farmer typologies. J. Dairy Sci. 98:4148-4161.

Meuwissen, T., B. J. Hayes, and M. E. Goddard. 2016. Genomic selection: A paradigm shift in animal breeding. Anim. Front. 6:6-14.

Miglior, F., A. Fleming, F. Malchiodi, L. F. Brito, P. Martin, and C. F. Baes. 2017. A 100-year review: Identification and genetic selection of economically important traits in dairy cattle. J. Dairy Sci 100:10251-10271.

Mrode, R., and G. Swanson. 1996. Genetic and statistical properties of somatic cell count and its suitability as an indirect means of reducing the incidence of mastitis in dairy cattle. Anim. Breed. Abst. 64:847-857.

Newton, J. E., M. E. Goddard, H. N. Phuong, M. A. Axford, C. K. M. Ho, N. C. Nelson, C. F. Waterman, B. J. Hayes, and J. E. Pryce. 2018. High genetic merit dairy cows contribute more to farm profit: Case studies of 3 Australian dairy herds. Proc. Anim. Breed. Genet. In press.

Nguyen, T. T. T., P. J. Bowman, M. Haile-Mariam, G. J. Nieuwhof, B. J. Hayes, and J. E. Pryce. 2017a. Implementation of a breeding value for heat tolerance in Australian dairy cattle. J. Dairy Sci. 100:7362-7367.

Nguyen, T. T. T., P. J. Bowman, M. Haile-Mariam, J. E. Pryce, and B. J. Hayes. 2016. Genomic selection for tolerance to heat stress in Australian dairy cattle. J. Dairy Sci. 99:2849-2862.

Nguyen, T. T. T., B. J. Hayes, and J. E. Pryce. 2017b. A practical future-scenarios selection tool to breed for heat tolerance in Australian dairy cattle. Anim. Prod. Sci. 57:1488-1493.

Nielsen, H.-M., L. G. Christensen, and A. Groen. 2005. Derivation of sustainable breeding goals for dairy cattle using selection index theory. J. Dairy Sci. 88:1882-1890.

Ortega, M. S., A. C. Denicol, J. B. Cole, D. J. Null, and P. J. Hansen. 2016. Use of single nucleotide polymorphisms in candidate genes associated with daughter pregnancy rate for prediction of genetic merit for reproduction in Holstein cows. Anim. Genet. 47:288-297. https://doi.org/10.1111/age.12420.

Parker Gaddis, K. L., J. Cole, J. Clay, and C. Maltecca. 2014. Genomic selection for producer-recorded health event data in US dairy cattle. J. Dairy Sci. 97:3190-3199.

Pryce, J. E., O. Gonzalez-Recio, G. Nieuwhof, W. Wales, M. Coffey, B. Hayes, and M. Goddard. 2015. Hot topic: Definition and implementation of a breeding value for feed efficiency in dairy cows. J. Dairy Sci. 98:7340-7350.

Pryce, J. E., and M. Shaffer. 2018. Cost benefit analysis of a dairy genomic reference population. Pages 1-4 in Proc. World Congr. 
Genet. Appl. Livest. Prod., Massey University of New Zealand, Auckland, New Zealand.

Ramsbottom, G., A. Cromie, B. Horan, and D. P. Berry. 2012. Relationship between dairy cow genetic merit and profit on commercial spring calving dairy farms. Animal 6:1031-1039.

Ravagnolo, O., and I. Misztal. 2000. Genetic component of heat stress in dairy cattle, parameter estimation. J. Dairy Sci. 83:2126-2130.

Ravagnolo, O., and I. Misztal. 2002. Effect of heat stress on nonreturn rate in Holsteins: Fixed-model analyses. J. Dairy Sci. 85:31013106.

Tiezzi, F., and C. Maltecca. 2015. Accounting for trait architecture in genomic predictions of US Holstein cattle using a weighted realized relationship matrix. Genet. Sel. Evol. 47:24.

van Knegsel, A. T., S. van der Drift, M. Horneman, A. de Roos, B. Kemp, and E. Graat. 2010. Short communication: Ketone body concentration in milk determined by Fourier transform infrared spectroscopy: Value for the detection of hyperketonemia in dairy cows. J. Dairy Sci. 93:3065-3069.

Vandenplas, J., M. Spehar, K. Potocnik, N. Gengler, and G. Gorjanc. 2017. National single-step genomic method that integrates multinational genomic information. J. Dairy Sci. 100:465-478.

VanRaden, P. M., M. E. Tooker, J. R. O'Connell, J. B. Cole, and D. M. Bickhart. 2017. Selecting sequence variants to improve genomic predictions for dairy cattle. Genet. Sel. Evol. 49:32.

Weigel, K. A., R. Pralle, H. Adams, K. Cho, C. Do, and H. White. 2017. Prediction of whole-genome risk for selection and management of hyperketonemia in Holstein dairy cattle. J. Anim. Breed. Genet. 134:275-285.

Weller, J. I., E. Ezra, and M. Ron. 2017. Invited review: A perspective on the future of genomic selection in dairy cattle. J. Dairy Sci. 100:8633-8644. 